\title{
Managing HIV/AIDS in the South African Workplace: Just Another Duty? ${ }^{1}$
}

\section{David Dickinson}

Wits Business School, University of the Witwatersrand

\section{ABSTRACT}

The vast majority of HIV and AIDS cases are located in sub-Saharan Africa. AIDS constitutes a critical threat to the development of South Africa, yet the response to date has been slow and often confused. The research of 'Deco' is examined to outline how the company approached HIV/AIDS. Deco's policies encouraged voluntary testing and counselling, openness and disclosure. Different HIV/AIDS programme aspects that responded in a reactive and underresourced way and lacking access to managerial structures, had the opposite results. The very real value of AIDS volunteers' contribution, is then described and evaluated. A new approach from both management and employees is needed in which a co-ordinated division of responsibility forms a key element in a workplace partnership to combat HIV/AIDS.

JEL J53, M14

\section{INTRODUCTION}

AIDS presents a major challenge to the creation of a prosperous South Africa in which all citizens are able to fulfil their potential. Yet the response to HIV and AIDS has been slow, fragmented, and often confused. At the heart of this failure lies a lack of effective national co-ordination (Campbell \& Williams, 2001; Marais, 2000; Schneider \& Stein, 2001). Beyond this however, the limited response from other sections of society is also striking. Despite a clear economic case for intervention (Booysen \& Molelekoa, 2002), business has largely failed to take a lead in this crisis. According to the South African Business Coalition on HIV/AIDS (Sabcoha) (2002), the majority of companies have yet to assess the risk within their own workforces, let alone begin to mount a response to this risk.

The Medical Research Council (2001: 5-6) argues that South Africa is experiencing an HIV/AIDS epidemic of "shattering dimensions" and that "the rapid change in the empirical death rates confirm predictions of the profound impact of AIDS on mortality." It is becoming too late not to act. In seeking to 
respond - with or without a national framework - business can draw on guidelines, such as the Nedlac negotiated Code of Good Practice on Key Aspects of HIV/AIDS and Employment (Nedlac/Department of Labour, 2000). However guidelines such as the Nedlac code, while valuable in terms of providing appropriate policy and objectives, do not guide business in terms of policy implementation. This requires a multiplicity of concrete actions, in often complex and localised environments. Such actions take the organisation beyond the formal adoption of policy. As companies scramble to upgrade or introduce their own response to HIV and AIDS, the reality of the epidemic demands not only good policies be in place, but also that HIV/AIDS programmes in the workplace - and beyond - are effective.

To date there have been few publicly-disseminated objective evaluations of workplace-based HIV/AIDS programmes in South Africa. With the exception of the Eskom 'best practice case study' (Department of Health, 1999) most reports on companies' responses to HIV/AIDS have either been corporate publications written with public relations in mind (for example, Anglo Gold, 2002), or critiques written largely from an outside perspective (for example, Meeson, 2000; Meeson \& van Meelis, 2000). These sources of information are important and are to be welcomed, but they are limited in their ability to tease out the actual problems of implementation - policy vs. practice - in a way that will help improve workplace responses ${ }^{2}$.

This paper draws on independent research within 'Deco,' a large South African corporation. It examines the interplay of official policies on HIV/AIDS and the actual practices of HIV/AIDS programmes, thereby providing lessons on the implementation of HIV/AIDS programmes in the workplace. In doing so it also raises the question of how HIV/AIDS in the workplace should be approached. Is HIV/AIDS simply another management duty that can be dealt with in a similar way to other management challenges? Or is there a need for a different approach?

\section{HIV/AIDS IN THE WORKPLACE}

The AIDS pandemic originated approximately twenty years ago. Its origins are uncertain. At this stage the HI virus responsible for AIDS continues to spread. Currently the highest levels of prevalence (infection) and the largest numbers of HIV+ individuals are in sub-Saharan Africa. It is likely that countries in Asia will in time replace Africa as the epicentre of the pandemic in absolute numbers.

While knowledge of HIV/AIDS and its prevention is often good, there is frequently a failure or reluctance to act on this knowledge (Williams et al, 
2000). Where the primary transmission route is sex, infection is embedded within powerful human drives and resilient cultural norms. It has proven extraordinarily difficult to change behaviour with a view to reducing infection (UNAIDS, 1999). Despite this, understanding of HIV/AIDS remains central to any response ${ }^{3}$.

HIV prevalence in South Africa is measured by actuarial extrapolations of tests carried out in state antenatal clinics on an annual basis. Because of the necessary assumptions required to generate a model representing the entire population, there is room for uncertainty over the exact levels of HIV infection. The trends, however, are clear. HIV infection among those sampled in the antenatal surveys has risen from 0,8 percent in 1990, when the studies were first started, to 24,8 percent in 2001 (Department of Health, 2002). The estimated incubation period of the HI virus in South Africa is 6-8 years. Given historical patterns of infection, large numbers of people are now showing AIDS symptoms and are dying (Medical Research Council, 2001). The situation will continue to deteriorate as the peak of the AIDS epidemic is not predicted to occur for some years (Actuarial Society of South Africa, 2000).

A key concern for companies is that AIDS, because of its sexual transmission, affects those of working age. What percentage of employees are HIV+ is, however, unclear. This is largely because of the limited number of prevalence surveys conduced by companies to date (Sabcoha, 2002), but also because of the reluctance of companies to release this data when it has been collected. Johnson and Budlender (2002) used prevalence data from four surveys, including one in a 'large company,' to evaluate HIV risk factors. They conclude that skilled and managerial employees are at low or very low risk, depending on the socioeconomic profile of their community, and that semi-skilled or unskilled employees are at medium or very high risk, again depending on the socioeconomic profile of their communities. The Botswana-based mining company Debswana survey of 74 percent of employees across its operations revealed a prevalence rate of 22 percent in 2001, with rates of over 30 percent for lower skilled employees (UNAIDS, 2002b). Anglo Platinum (2002) reported in its 2002 Annual Report, in line with the King II Report (2002) guidelines, an estimated HIV prevalence rate among its employees of also 22 percent.

HIV/AIDS impacts on companies in a number of ways and estimating the scale of these is complex (UNAIDS, 2002b). The primary impact is on employee's ability to work effectively as they become ill. This lowers productivity (of the individual and of co-workers) and raises absenteeism. Replacement of workers that die from AIDS involves recruitment and training costs, in addition to lower levels of productivity before the new employee gains experience. Other considerations, within the workplace, are the impact of AIDS illness and death 
on medical, insurance, and pension provision (Rosen et al., 2000). Outside the workplace there are implications for markets as expenditure contracts and shifts in relation to the impact of AIDS on individuals, families, and communities (Barnett \& Whiteside, 2002).

Guidelines for responding to HIV/AIDS in the workplace (such as the Nedlac Code of Good Practice referred to in this article) balance prevention of HIV infection with care for those already infected. One of the central dilemmas in providing treatment is the cost of antiretroviral drugs. While employees on medical aid schemes often have access to managed antiretroviral drug treatment, those without medical aid schemes do not, nor are they generally in a position to fund such treatment directly. Given the benefits for the company and individual of effective treatment, a number of South African companies have recently announced schemes providing antiretroviral drugs to their employees and, in some cases, dependants.

\section{DECO}

Deco is a large South African corporation with over 25,000 South African employees. The company is divided into a number of major 'divisions' that operate in a number of diverse production processes. These divisions - some of which are divided into smaller 'business units' - are located within a small number of large industrial complexes. The largest division, in terms of employees, is its mining operation.

Deco's management is predominantly Afrikaans. An engineering background is strongly valued within the company. This technical orientation supports 'hard' workplace issues, such as Health \& Safety, as well as providing formidable capacity for project development. By contrast, management tends to struggle with 'softer' workplace issues, such as employment equity. The company employs a large number of predominantly white skilled blue-collar workers, such as artisans. Approximately 44 percent of the Deco workforce is white (85 percent of management and 37 percent of lower grades). Lower grades, such as miners and process controllers, are predominantly African. Only 12 percent of the company's workforce is female, distributed roughly equally between management and lower grades.

The are three major unions operating in Deco, two are affiliated to national federations, Cosatu and Nactu. These two unions represent predominantly black semi-skilled workers. Their memberships are geographically distributed and high membership densities at different sites give both unions influence. The third union, Solidarity, represents predominantly white members - much of 
Deco's skilled blue-collar employees - giving the union considerable power. Five other smaller unions also operate within Deco.

\section{METHODOLOGY}

Given the nature of the research question - the practice of implementing HIV/AIDS programmes in the workplace - the methodological employed was both quantitative and qualitative in nature. A number of South African companies were approached for research access, but only Deco responded positively. Even here the company approached research access with caution and a comprehensive Research and Confidentiality Agreement was negotiated.

This caution was engendered in part by the sensitive nature of HIV/AIDS and the fear that research findings might prove to be damaging to the company. The company, and in particular members of its labour relations department (acting as 'principals' to the researcher), balanced this fear of negative publicity against the need to know what the company was doing in response to HIV/AIDS and whether it was effective - something that independent research would assist in doing. Beyond this desire for internal information was a realisation that such research could be of wider benefit.

The research consisted of a questionnaire sent out to all Deco's divisions and, in some cases, the business units within these divisions. The questionnaire requested basic details on the workplace and on the response mounted to HIV/AIDS within it. This latter aspect included asking respondents to evaluate their implementation of twelve aspects of best practice programmes drawn from the Nedlac Code of Good Practice. Respondents had five levels of implementation to choose from, ranging from 'no action taken or currently planned' to 'aspect complete'. These programme aspects (re-organised to assist analysis) are listed below.

\section{Twelve programme aspects drawn from the Nedlac negotiated Code of Good Practice on Key Aspects of HIV/AIDS and Employment}

- $\quad$ HIV/AIDS awareness programmes

- $\quad$ Promotion of condom distribution and use

- Provision of access to counselling for people affected by HIV/AIDS

- $\quad$ Education and training on HIV/AIDS

- $\quad$ Encourage treatment of sexually transmitted infections (STIs) ${ }^{4}$

- Enforce the use of infection control measures to ensure HIV is not acquired in the workplace

- A 'wellness' programme for employees 
- Monitoring, evaluation and review processes of HIV/AIDS workplace programmes

- $\quad$ Encouraging and offering voluntary counselling and testing (VCT) ${ }^{5}$ for HIV

- Create an environment that is conductive to openness, disclosure and acceptance of HIV/AIDS among all staff

- Maximise the performance of affected employees through 'reasonable accommodation'

- Development of strategies to deal with the direct and indirect costs associated with HIV/AIDS in the workplace.

Because of company backing for the research, all questionnaires were completed and returned - representing 18 divisions and business units. Nineteen observations were collected for the implementation of the twelve HIV/AIDS programme aspects as one business unit split its response over two geographical locations. Given the different sizes of divisions and business units across the company, questionnaire responses reflect not the number of employees exposed to these programmes, but the scope of the various HIV/AIDS workplace programmes within the company.

The questionnaires were then followed up by in-depth interviews with the senior human resources manager of divisions or business units and with the employees most involved with the workplace's response to HIV/AIDS. These individuals occupied a wide range of positions within the company and included human resource managers, medical personnel, industrial social workers, industrial relations officers, corporate social investment personnel, a secretary, and production workers. In addition to raising qualitative issues these interviews shed light on the questionnaire responses. One key fact in this respect was that questionnaire responses were often optimistic in their evaluation of programme implementation. Typically, the reported level of implementation might be occurring in some areas of the division or business unit but not in others. Thus, analysis of these programmes in this article draws both on the questionnaire responses and the in-depth interviews. In addition to interviews with human resource managers and individuals implementing HIV/AIDS workplace programmes, in-depth interviews were conducted with representatives of the three main unions operating in Deco and with a number of doctors employed by or contracted to Deco. In total more than 40 interviews were conducted between September 2001 and February 2002.

Data from the questionnaire and interviews were supplemented by documentary information. Further qualitative information was collected during attendance at the company's Corporate HIV/AIDS Forum and other meetings. As with all successful qualitative workplace studies, a number of individuals central to the 
process being investigated emerged as key 'narrators' for the researcher. These individuals took it upon themselves to explain to the researcher - on an ongoing basis - the wider dynamics of the company within which the response to HIV/AIDS was embedded. Without this information it would have been much harder to understand many processes and events.

\section{DECO'S RESPONSE TO HIV/AIDS}

As with the majority of South African companies, Deco's response to HIV/AIDS came late in the epidemic. The company's first official policy on HIV/AIDS was developed in 2000 and launched on World AIDS Day ( $1^{\text {st }}$ December) of that year. This policy 'talked the talk' and reflected best practice guidelines publicly available. Specifically the policy guidelines for the company were:

- $\quad$ Ensure awareness and understanding of the AIDS epidemic;

- $\quad$ Offer voluntary and confidential counselling and testing;

- Equip line managers, supervisors and human resources to deal with the impact of the disease;

- $\quad$ Treat sexually transmitted diseases (STIs) and dispense free condoms;

- Educate its employees about how to take care of themselves in order to remain fit and healthy;

- $\quad$ Support people with HIV or AIDS for as long as possible by teaching them about positive living and the value of a good diet and regular exercise.

The late adoption of the company's HIV/AIDS policy meant that it lagged behind the actual implementation of HIV/AIDS programmes in many of the company's divisions and business units. A key implication of this was the decentralised nature of the actual response, with individual workplaces responding to the threat of HIV/AIDS without the benefit of strong central guidance. The nature and extent of these responses was influenced by two key factors - the visibility of AIDS within the workforce and the initiative taken by individual employees.

Deco's mining division provides an example of where the high visibility of AIDS prompted an early response. This visibility resulted from two factors. Much of the mining workforce was low-skilled, low-paid, and often migratory and at high risk in terms of HIV/AIDS. The higher prevalence within the mining workforce (estimated at approximately 21 percent in 2002) was made evident by the division's centralised health care services. In contrast with other Deco employees, some 5,500 miners within Deco's mining division's 8,500 
employees did not have access to the company's medical aid scheme. Rather, health care was provided by the mine hospital, which also conducted the annual health checks legally required for underground workers. This systematic medical contact with a high-risk workforce led to the early identification of HIV and AIDS as a problem for mining and prompted the earliest and most comprehensive response to HIV/AIDS within Deco.

Other Deco divisions and business units had lower estimated risk profiles than the company's mining operations - ranging from a few percent for professional workplaces such as the company's head office, to the mid-teens for workplaces where larger numbers of low-skilled workers were employed. In these latter workplaces it appears that the visibility of HIV/AIDS had been masked by the decentralised nature of health care and the absence of annual health checks. Spread out among different doctors away from the workplace, early AIDS cases had tended to go unnoticed - and certainly not collated - by the company.

In situations like these where AIDS has not been visible the response tended to reflect the commitment of individuals within the workforce who took it upon themselves to act. In many situations this was possible because, until recently, the low priority afforded to HIV/AIDS by the company meant that senior managers devolved responsibility for HIV/AIDS downwards. This devolving of responsibility often continued until somebody picked up the challenge for reasons other than their job description or career advancement prospects. Medical sisters, for example, were often influenced by their contact with workers presenting AIDS-related symptoms at medical stations. However, the overriding reason for such unofficial 'AIDS volunteers' within Deco was the realisation that HIV/AIDS represented a social tragedy not only for Deco workers, but also for their communities and the country as a whole. There was a sense that 'something had to be done.'

The 'bottom-up' responses mounted within the company are discussed later. However, one important point relevant to the overall response of Deco is that the junior status of many of these AIDS volunteers meant that responses were often localised and limited in nature. The tendency towards localisation was exacerbated by the complex geographical spread of some divisions and business units. Without access to senior managers and resources, bottom-up responses tended to focus on the immediate workplace - resulting in gaps in the implementation of the HIV/AIDS programme across the division or business unit as a whole. The absence of backing from senior management also constrained the scope of programmes. While the attitudes of line management was often identified as a key problem by AIDS volunteers they did not have the authority to integrate their programmes into management hierarchies that would include line managers. 
One response to HIV/AIDS that was centralised - though not from within the company - was the provision of anti-retroviral drug treatment for members of the company's medical aid scheme. This was provided via scheme's administrators who offered an HIV/AIDS disease management programme. This programme allows members to access managed anti-retroviral drug therapy and vitamin supplements. Such programmes work best when HIV+ employees access benefits prior to them entering the AIDS phase of the disease. Asymptomatic HIV+ employees can, if registered on the programme, be monitored on a regular basis and anti-retroviral treatment commenced prior to the need for expensive hospitalisation. However, as the following table illustrates, even where Deco workers have access to anti-retroviral drugs via their medical aid scheme only a fraction of the estimated HIV+ workers in Deco have yet used their medical aid to establish their HIV status or register on the programme.

\section{Table 1 Deco employees utilising the HIV/AIDS management programme $^{6}$}

\begin{tabular}{|l|c||}
\hline $\begin{array}{l}\text { Employees with access to HIV/AIDS management } \\
\text { programme }^{7}\end{array}$ & 20,500 \\
\hline $\begin{array}{l}\text { Employees with access to HIV/AIDS management } \\
\text { programme that are } \text { estimated }^{8} \text { to be HIV+ }\end{array}$ & 2,000 \\
\hline $\begin{array}{l}\text { Employees that have used the HIV/AIDS management } \\
\text { programme for CD4 and viral load tests }\end{array}$ & $540^{10}$ \\
\hline $\begin{array}{l}\text { HIV+ employees that are currently registered on the } \\
\text { HIV/AIDS disease management programme }\end{array}$ & 200 \\
\hline $\begin{array}{l}\text { Employees who had disclosed their HIV+ status within } \\
\text { the workplace }\end{array}$ & $1-2$ \\
\hline \hline
\end{tabular}

This limited take up of available treatment indicates that even where a coherent centralised programme is in place if this is not supported by other programmes its effect will be limited. Accessing the HIV/AIDS management programme requires that employees, first, know that the programme is available and know their HIV status and, second, are not discouraged from accessing it through fear of AIDS, confidentiality, stigma, or a belief that they will be discriminated against should their status become public knowledge. Without a wider, coordinated HIV/AIDS programme across the company, any individual programme, however good, is likely to be only partially effective.

Ironically, the Deco division that first identified the problem of HIV/AIDS within its workforce - mining - did so, in part, because it did not have medical aid cover, and hence access to the HIV/AIDS disease management programme, for many of its workers. Unlike the company's medical aid scheme, mining's 
health care system, provided through the mine hospital does not include the provision of anti-retroviral drugs for workers or their dependants (though it does provide treatment for opportunistic infections as part of an extensive healthcare programme). Provision of anti-retroviral drugs for this group of workers is currently being considered, but is hampered by the group's low income and the high cost of drugs and drug administration.

The company's generally fragmented approach to HIV/AIDS and the fact that responsibility had been largely devolved to relatively junior employees was reflected in the composition of Deco's Corporate AIDS Forum. The Forum, established in 1999, was a valuable resource for information sharing between those carrying out HIV/AIDS programmes, but it lacked the authority to impose a comprehensive strategy on the company as a whole. At the beginning of the research period the composition of the Forum was noticeably atypical of Deco management - being numerically dominated by women and predominantly black. Indeed, it was clear that while the Forum members saw themselves as part of Deco they did not see themselves as management (despite the fact that many of them were). Rather, 'management' was viewed as a group hampering their objectives. Numerous discussions focused on how 'they' (management) had to be convinced that HIV/AIDS was a major problem that the company needed to confront.

Within the research period the profile of HIV/AIDS within Deco rose rapidly. This was due to a number of factors, including pressure from the wider environment, the work of Forum members, a knowledge, attitudes and practices (KAP) survey in the company's mining division, the carrying out of a companywide HIV/AIDS risk assessment and the author's research project. As a result of this, more senior (and therefore white male) managers joined the Forum. These newcomers were welcomed by the existing Forum members as reflecting a shift in the company's thinking over HIV/AIDS as well as for the capacity that they brought to the group. At the same time, however, the close and supportive relationships previously established within the Forum started to shift as a more orthodox managerial approach began to dominate meetings.

Late in the research period a further shift was evident. The formal prioritisation of HIV/AIDS at the highest levels of the company was illustrated by the company's new senior human resources manager been given responsibility for championing the response to HIV/AIDS. Significantly, this manager had previously been MD of the Deco's mining division - where the impact of HIV/AIDS was most apparent. A consulting company was tasked by the new human resources manager to review Deco's existing practices, develop a business case for responding, and design new and improved solutions that could be rolled out across the company's South African operations. All this amounted 
to a new, externally influenced, more co-ordinated and better-resourced response by Deco to HIV/AIDS.

Thus, a high-level, well-resourced implementation team has been superimposed upon the largely decentralised and varied response generated from the grassroots in Deco. The rest of this article looks at what had been achieved within Deco before this shift occurred. The strengths and weaknesses of this response are informative for what they tell us about the reality of implementing good policy. They also draw attention to the challenges that the current, more managerially powerful, approach to HIV/AIDS now been undertaken in Deco face. This new approach needs to address the weaknesses of the company's current response to HIV/AIDS while harnessing - and not destroying - its existing strengths.

\section{HIV/AIDS PROGRAMMES AT DECO}

This section looks at the implementation of the twelve HIV/AIDS programme aspects of the Nedlac Code of Good Practice by Deco divisions and business units, as outlined in Section 4. The responses to the questionnaire provide a platform for analysis that is, critically, informed by qualitative information obtained during the in-depth interviews. The figures following each aspect collapses the possible response options into either 'No' for no implementation having taken place, or 'Yes' for some implementation having taken place - out of a total population of 19 workplaces. Because of the important role of supplementary, qualitative information, the quantitative responses indicated correspond to, but do not determine, the categories employed. Additionally, the figures need to be considered in the light of the often over-optimistic reporting of implementation that in-depth interviews revealed.

\subsection{The easy part: Awareness, condoms, and counselling}

\section{The three aspects of HIV/AIDS programmes that were reported by Deco divisions and business units as most successfully implemented were:}

- HIV/AIDS awareness programmes: Yes 15 (79 per cent), No 4 (21 per cent);

- $\quad$ Promotion of condom distribution and use: Yes 16 (84 per cent), No 3 (16 per cent); and

- Provision of access to counselling for people affected by HIV/AIDS: Yes 15 (79 per cent), No 4 (21 per cent).

This first tier of a HIV/AIDS programme - awareness, condoms, and counselling - represented policy aspects that can be relatively easily achieved. 
At a minimum, World AIDS Day events, condom dispensers in the toilets, and an Employee Assistance Programme (EAP) (whereby service providers offer a toll free advice number and access to counselling for a monthly fee) allow these aspects of HIV/AIDS policy to be ticked off as 'functioning smoothly'. While such interventions should not be belittled, on their own they represent only a minimum level of activity taken in response to a vaguely perceived problem. Such activities could be undertaken without undue inconvenience to the work of the division or business unit. Thus, such actions can be regarded as a good 'first step' in the development of a workplace programme to deal with HIV/AIDS, but not more than this.

\subsection{Not quite so easy: Education and training, STI treatment, and preventing occupational infections}

A second tier of HIV/AIDS programmes that respondents claimed to have successfully implemented or to be implementing - though to a lesser extent than awareness, condoms and counselling - consisted of:

- $\quad$ Education and training on HIV/AIDS: Yes 14 (74 per cent), No 5 (26 per cent);

- $\quad$ Encouraging treatment of STIs: Yes 11 (58 per cent), No 8 (42 per cent);

- Enforcing the use of infection control measures to ensure HIV is not acquired in the workplace: Yes 12 (63 per cent), No 7 (37 per cent); and

- A 'wellness' programme for employees: Yes 9 (47 per cent), No 10 (53 per cent).

That these programmes are being implemented, though somewhat behind 'awareness, condoms and counselling,' is instructive and supports the idea that HIV/AIDS programmes are often driven by the ease of implementation, rather than an objective assessment of their effectiveness or efficiency.

Education and training requires a greater level of resources than awareness World AIDS Day events, for example, would not constitute education and training. Given this, it is not surprising that the level of implementation of education and training programmes lagged slightly behind that of the awareness programme.

The role of STIs as a co-factor in the transmission of HIV is well known and STI treatment reduces HIV transmission without behavioural change. Explaining why STI treatment - despite its efficacy - lagged behind condom distribution is also explained by the question of resources. Whereas condom distribution can be managed without medical personnel, the treatment of STIs, demands medical expertise which was not always available. Additionally, while medical personnel 
were actively involved in HIV/AIDS programmes in a number of Deco workplaces where they have organised the treatment of STIs in other workplaces medical personnel consciously did not provide this service. This was due to a number of factors, including the costs involved, the 'unpleasant' nature of STI treatment, and moral uncertainties over whether STIs should be treated in workplace facilities given that such treatment cannot require the treatment of partners (as government health facilities often do).

In light of Deco's strong emphasis on Health \& Safety, it was surprising that a number of Deco's workplaces reported that they had not yet fully implemented infection control measures to ensure that HIV was not acquired in the workplace. To an extent this apparent lack of concern over the issue may have reflected a well-founded understanding that, while the risk of occupational exposure to HIV does exist, the workplace is not the primary location of HIV transmission. This is especially so in white-collar workplace environments that do not involve machinery and the use of hand tools.

However, it was also likely that aspects such as infection control measures (e.g. rubber gloves in first aid kits) have been implemented, but as part of ongoing Health \& Safety activity, not as a specific HIV/AIDS programme. If so, it indicates that responsibility for HIV/AIDS programmes lay outside of shop floor management and that there was little communication between them and those dealing with HIV/AIDS.

Finally, respondents interpreted the question on wellness programmes differently from one another. Some regarded an Employee Assistance Programme as counting as a wellness programme - and therefore indicated on the questionnaire that such a programme was in place. Others interpreted a wellness programme more rigorously - as a proactive programme designed to educate and help people to improve their diets, reduce stress, and live more balanced lives. Most divisions and business units did not have such programmes in place ${ }^{13}$.

\subsection{Does it work? The need to monitor}

A minority of Deco's workplaces reported having 'monitoring, evaluation and review processes' in place for their HIV/AIDS programmes (Yes, 7 (37 per cent), No 12 (63 per cent)). To some extent this weakness can be ascribed to the relatively short histories of some of the programmes being implemented. However, some programmes had been running for a number of years without any monitoring or review. 
The absence of monitoring, evaluation and review of an on-going programme is a sign of weakness in implementation. This is true for any workplace intervention, but it is especially true in the context of HIV/AIDS and the known difficulty in changing sexual behaviour. Three explanations can be offered for this weakness.

First, as outlined above, a number of workplace programmes had been established with little real backing and, as such, existed as a 'bare bones' response to show that something was being done. Second, those individuals who had picked up the challenge of responding to HIV/AIDS in Deco often lacked the managerial expertise that would have ensured that they monitored the effectiveness of their own interventions. Third, it may be the case that limited and uncertain funding for these processes did not encourage budgeting for monitoring.

\subsection{Testing, disclosure, and accommodation}

Three programme aspects - testing, disclosure, and accommodation - interlock and together form the most difficult and complex aspect of any response to HIV/AIDS. These are:

- $\quad$ Encouraging and offering VCT: Yes 6 (32 per cent), No 13 (68 per cent);

- Creating an environment that is conducive to openness, disclosure and acceptance of HIV/AIDS among all staff: Yes 11 (58 per cent), No 8 (42 per cent); and

- Maximising the performance of affected employees through 'reasonable accommodation': Yes 8 (42 per cent), No 10 (58 per cent), Don't Know 1 (5 per cent).

These three aspects of an HIV/AIDS programme support each other: VCT is a precursor to disclosure and disclosure is more likely if HIV+ employees are being supported - through, for example, 'reasonable accommodation' (whereby steps are taken to provide alternative, lighter duties) in their work. However, the implementation of these three aspects of HIV/AIDS policy varied. A number of workplaces claiming to have created a conducive environment for openness and disclosure yet had not taken steps to encourage VCT, nor put in place policies to maximise the performance of affected employees.

In a large number of workplaces VCT was not encouraged, or was noted as 'planned, but not implemented to date.' In-depth interviews revealed that this was often a result of confusion over whether any form of testing was permissible. Encouraging people to go for voluntary counselling and testing (VCT) is legal, desirable and good for the company and its employees (as well 
as being part of the Nedlac's Code of Good Practice). The provision of VCT services by companies is an issue currently caught in a conflict between the Code of Good Practice and the Employment Equity Act (Government, 1998) that the code is derived from ${ }^{14}$. Many managers, often those actively working on HIV/AIDS programmes, appeared to be confused over VCT. This confusion stemmed largely from issues unrelated to the conflict between the Code and Act, but from an earlier company initiative to conduct prevalence testing that unions, fearing discrimination, had blocked. As a result, these managers had effectively 'thrown the baby out with the bath water' and were steering clear of anything to do with testing.

Very few Deco employees had voluntarily disclosed their status. Only one case of an openly HIV+ person was reported to the researcher, while another was beginning to come forward within a limited circle towards the end of the research period. (The first employee who disclosed her status was subsequently ostracised by her co-workers). The status of a number of other HIV+ Deco workers had been revealed, but only because the person was in an advanced AIDS stage and denial or concealment was no longer possible. While workplaces reported, via the questionnaire, significant progress in creating an environment conducive to openness and disclosure, many interviewees expressed frustration that people were not willing to disclose their status. One immediate explanation for this frustration was the failure to implement policies - such as encouraging testing and supporting those with HIV/AIDS - that would support disclosure. Thus, creating an atmosphere in which openness and disclosure of individuals HIV status is only possible if concrete steps to support this are implemented in tandem to programmes that simply encourage this as a 'good thing.' In addition to this need for inter-linked policies to be implemented in tandem, some of the structural reasons why openness, disclosure and acceptance do not appear to have been achieved, despite efforts on the part of some managers to ensure such an environment, are discussed later (see Section 7).

\subsection{Strategies to deal with the costs of HIV/AIDS}

The vast majority of Deco workplaces responded to the aspect of 'development of strategies to deal with the direct and indirect costs associated with HIV/AIDS in the workplace' by reporting that no action had been taken (Yes 3 (16 per cent), No 15 (79 per cent), Don't Know 1 (5 per cent)). That this was the least implemented of all twelve HIV/AIDS policy aspects is interesting, especially in a company with high levels of managerial capacity in which management risk analysis and contingency planning is commonplace in relation to other issues. A number of explanations for this can be put forward. 
First, where managers perceive there to be little risk to their workforce - and therefore, low potential cost to their business - there is no pressing need to make preparations. This appeared to be the perspective held by some, though not all, interviewees in white-collar workplaces where in-depth interviews were conducted. Second, even where the potential impact of AIDS was recognised, it was often placed in the context of overall labour turnover. In some workplaces this led to AIDS being viewed as a contributing but not critical factor in determining labour requirements. In this context special preparation to mitigate the costs of HIV/AIDS was not seen as necessary over and above existing policies. Third, while some interviewees thought that the costs of HIV/AIDS might be significant, the limited information available on HIV/AIDS in their workplaces meant that it was not possible to implement plans to deal with the cost of HIV/AIDS.

Finally, many human resource managers, when interviewed, revealed that they had put considerable thought into possible - but uncertain - skills shortages as a result of AIDS. Often, their answers to questions during the in-depth interviews demonstrated innovative responses to uncertain skills requirements while bearing in mind the need to maintain budget parameters. Whether these responses could all be successful - in the event that a number of Deco's workplaces found themselves needing to rapidly and simultaneously recruit skilled and semi-skilled workers from the same, localised, labour markets - is questionable. However, the obvious capacity and careful thought demonstrated by human resource managers, compared to the level of response indicated in the questionnaire, was in itself instructive and raises again the important point about the lack of co-ordination between different players in the response to HIV/AIDS. Put simply, in-depth interviews revealed that human resource managers tended to fill in those sections of the questionnaire related to workforce statistics, while the questions on HIV/AIDS programmes were completed by the other individuals - often not human resource managers - who were responsible for such programmes. Human resource managers were thinking about the possibility that they might need to find replacement labour as a result of AIDS, but this seems not to have been apparent to many of those actually dealing with HIV/AIDS in the workplace.

\section{STIGMA AND THE STRUCTURES OF DISCRIMINATION}

HIV/AIDS is a heavily stigmatised disease. This is largely due to the fact that it is sexually transmitted, loading infection with moral and cultural judgements. Even when such judgements can be put aside, sex remains for many people an embarrassing topic that is difficult to discuss openly. The absence of a cure for AIDS - and the even greater ignorance of the positive steps that infected 
individuals can take to remain healthy - makes HIV/AIDS a feared disease and reinforces its stigmatised status.

Such stigma is independent of the workplace, being generated from wider social values and the nature of the disease. Nevertheless, it was apparent during the research that a number of structures within Deco (which are described below) have established dynamics that reinforce the stigma attached to HIV/AIDS despite the company's stated policy that:

It is essential that an environment be created in which an employee living with HIV or AIDS is able voluntarily to divulge his/her status without fear of discrimination or retribution. Such an environment will assist management not only to support the employee where possible, but importantly also to manage the human resources implications (Deco, 2000).

As Table 1 illustrated, of the estimated two thousand HIV+ Deco employees with access to anti-retroviral drugs only 200 were registered for the medical aid HIV/AIDS programme. Finally, as previously mentioned, only one employee had openly disclosed her status at work, while another appeared to be on the brink of doing so.

This state of affairs is clearly undesirable. When employees do not access available medication, the company is likely to loose valuable employees. Despite the availability of anti-retroviral drugs, a number of interviewees reported cases of employees who had not accessed anti-retroviral drugs, but instead had concealed AIDS symptoms until they had literally collapsed on the job and had to be hospitalised. At this point the use of anti-retroviral drugs may well be too late (Ward, 1999). Such people represent bad role models since they send a message that AIDS is a death sentence. By contrast, individuals who find out their status, take positive action to deal with it and talk openly about what they have done, provide positive role models and send a message that it is possible to live and work productively with HIV. People living openly with HIV are an important resource for any HIV/AIDS programme; their testaments at meetings are powerful, and often electrifying. Their impact is clearly all the more effective when they speak from within the company - rather than as invited outsiders - since they face the same difficulties as fellow employees who may be afraid to know or reveal their status.

Structures of discrimination were not intentionally designed to exclude those with HIV/AIDS - indeed they sometimes arose from well-intentioned policies and practices. But these structures of discrimination, in combination with the wider stigma attached to HIV/AIDS, and the failure to implement the 
interlocking policies around disclosure in tandem, help explain the previously noted contradiction between reported progress in creating an environment conducive to disclosure and the actual cases of disclosure.

The fear of being sidelined in terms of training and promotion acted as disincentives for Deco's HIV+ employees to find out, respond to, or disclose their status. Interviewees identified line-management as a key problem in this respect. Line managers were reported as responding to HIV/AIDS on the basis of their own - often incomplete - understanding. For example, some supervisors had demanded disposable cups for sections where they suspected somebody might be HIV+. Such attitudes form a 'frontline' of workplace discrimination and translates into very real consequences over training and promotion decisions. Close to the shop floor, such outcomes operated below, and in opposition to, the supportive policy of the company. Thus, the wider stigmatisation of HIV and AIDS entered into the workplace not only through individual's reluctance to be identified as HIV+ because of the likely negative reactions of co-workers, but also because of fears that the attitudes of those directly above them would result in discrimination.

The consequential inaction on the part of HIV+ employees led to the effective denial of anti-retroviral drug treatment for many Deco workers. As such employees fall ill with AIDS-related symptoms their denial is maintained - or respected. Unless pro-active action is successfully undertaken to persuade them to access VCT for HIV, they proceed down the 'sick route' - in which a tacit agreement is maintained to deal with AIDS-related opportunistic infection, typically $\mathrm{TB}$, rather than the underlying cause. This eventually sees the employee medically boarded from the company on a pension or with a provident fund payout.

While humane in respecting individuals' wish not to disclose, the sick route is clearly sub-optimal for companies, especially where such employees have valuable skills. Such outcomes are also sub-optimal for employees who have not taken the most appropriate action to deal with their actual problem and who now face a reduction in income at a time when their own and their family's resources will be greatly stretched. In some cases this is complicated further by provident fund re-insurers instigating lengthy investigations into the degree of disability when, in fact, the worker has been sent home to die. It also reinforces fears, and therefore stigma, over HIV/AIDS among the remaining workforce as employees see fellow workers with AIDS $^{15}$ quietly dropped from the company into difficult home situations. Such processes feed back into the fear and stigmatisation of HIV/AIDS. This sets up a vicious circle in which merely establishing one's HIV status, let alone disclosing it, becomes increasing difficult, despite the existence of company policy encouraging VCT and disclosure. 


\section{THE IMPORTANCE OF 'AIDS VOLUNTEERS' WITHIN DECO'S RESPONSE}

The previous section discusses areas of policy that grassroots responses to HIV/AIDS were not in a strong position to address. The AIDS volunteers who mounted these responses were not able, for example, to challenge medical boarding processes and even less able to negotiate with provident funds. Nor, despite the company policy on AIDS, did they have the power to influence line managers who often formed the frontline of workplace discrimination. Such systemic problems clearly require a co-ordinated response supported by seniorlevel champions and backed by adequate resources - for example, ensuring that all line managers receive training on HIV/AIDS and are clearly instructed by their superiors that they must carry out company policy towards HIV+ employees based on this training.

Such weaknesses in the response mounted by these AIDS volunteers, should not, however, detract from the very real strengths that these individuals - and the groups and processes that they established - brought to the company. Compared to managerial-led processes, the strengths that such grassroots volunteers bring include a 'can do' approach to the daunting issue of HIV/AIDS and their ability to communicate on a peer basis with their colleagues and workmates.

The concept of peer communication is central to effective responses to HIV/AIDS (UNAIDS, 2000). Because our response and our vulnerability to HIV/AIDS is embedded within group attitudes and behaviours, effective understanding of the disease and changing behaviour is best achieved through discussions among peers. Successful peer educator initiatives therefore consist of a cross section of the company's employees - in terms of occupational level as well as demographic characteristics, such as race, age, and gender. This closeness to all levels of the company, combined with enthusiasm to address the issue, provides a powerful line of communication into the workforce that management - alone - simply cannot replicate ${ }^{16}$.

Within Deco a number of peer educator structures had been established - often with minimal support from management. In a sub-unit of the company's chemical division a secretary put together an 'AIDS Task Team' which included Afrikaans artisans, African shop stewards, and white female administrative staff. Meeting during lunchtimes, the group was obviously highly motivated and their report backs made it clear that they were engaging their fellow workers around the issue of HIV/AIDS on an ongoing basis. Such interactions were linked to a series of interventions that the Task Team undertook. Some of these ensured that best practice policies - such as condom distribution - were being carried out. 
While the team's projects were often driven by the gaps they saw in the company's response (such as the absence of condom dispensers in some buildings that they worked in), others were deliberately chosen to raise the profile of HIV/AIDS and provide opportunities for discussion. Towards the end of the research period, the Task Team launched its own research project with the aim of getting the 600 workers in their unit to complete a short survey on HIV/AIDS. This was carried out to establish the levels of knowledge on HIV/AIDS among the workforce. However, it also enabled the group to break out of its previously localised response and ensured that team members had direct contact with all their co-workers. After the questionnaires were completed for each shift in each workplace, team members were available to answer questions, a process that further cemented links between the Task Team and the wider workforce.

In another of Deco's large divisions a medical sister - without support from the senior doctor at her medical centre - organised a network of Peer Educators across all divisions and business units on site. On the wall of her office a large map of the plant with it various workplaces was covered with coloured pins that identified the location of this network. Using the medical centre she ran training sessions for volunteers and then kept in contact with them by providing condoms that they would come and collect - along with new publicity material on a regular basis. Interviewing one of these Peer Educators, a process controller in a different division, it was clear that he was using this training not only in the workplace, but also in his community. It was also evident that his regular contact with the sister when picking up condoms was an important source of support and information.

This peer educator was assisted by the management of his business unit, who had given him a slot at the 'coffee sessions' where shifts discussed production issues. However, it was also evident that there was a lack of co-ordination between the peer educator's efforts - backed by the bottom-up initiative run out of the medical centre - and the approach being taken by his management. This was manifested in an effective 'turf war' over who should be the first line of support for employees concerned about HIV/AIDS - the peer educators or the management-contracted EAP. This situation was not inherently conflictual having a number of sources of information on HIV/AIDS is desirable and, if coordinated, not a problem - but became so because of the failure to pull together different approaches to HIV/AIDS.

This example illustrates the need for elements of an effective HIV/AIDS strategy to be co-ordinated and supported from the centre of a company and for other elements to be delivered by volunteer-type grassroots structures. To some extent, Deco's mining division had made considerable progress in combining 
the 'top-down' and 'bottom-up' responses to HIV/AIDS in the workplace. While the division struggled with the problem of most of its workforce lacking access to anti-retroviral drugs, early identification of the problem among its workforce resulted in the appointment of a highly capable and motivated human resource manager to work alongside the mine doctor. Access to senior divisional management allowed the roll out of a programme for line manager education on HIV/AIDS. Mine managers were instructed to ask for volunteers from the workforce who were also trained as peer educators. These peer educators were organised into mineshaft committees that ran themselves, each taking different approaches to their task. In May 2002 a Peer Educator Day was organised with some 200 peer educators from the mines attending. Each group provided feedback on its programme and took questions from the other peer educators. A number of educational and inspirational presentations were made, including the preliminary results of a KAP survey that the human resource manager had commissioned to provide information on the workforce's understanding of HIV and AIDS.

\section{CONCLUSION: CHALLENGES AND OPPORTUNITIES}

The fragmented nature of Deco's initial response to HIV/AIDS is evident not only in its structures, but also in the implementation of programmes. The primary factors in the response to HIV/AIDS were the visibility of the disease within the workforce, the ease with which programme aspects could be implemented (rather than their effectiveness), and the presence of committed individuals whose motivation was drawn from outside the company's management priorities. This amounts to a reactive rather than proactive response, which appears to be typical of corporate South Africa's response to this epidemic to date.

Reports by managers that their workplaces represented environments conducive to disclosure of employees' HIV+ status contrasted sharply with the paucity of workers who had taken such steps within the company. This is instructive and drives home the point that having an HIV/AIDS policy is one thing, but that turning such a policy into a reality requires much more than a document. The low take-up of the confidential AIDS disease management programme available to most workers in Deco further underscores this point. Even policies backed by an appropriate programme may not be sufficient to ensure an adequate response in the area of HIV/AIDS. Because of the stigma, fear, denial, and discrimination that surrounds HIV and AIDS there needs to be a pro-active engagement with all employees using multiple - but above all, peer-based - channels of communication. Thus, policy and programmes need to be closely aligned with ongoing processes in which knowledge, attitudes and ultimately behaviour are 
shifted through continuous debate and discussion within employee groups. Such an approach requires the mobilisation of grassroots structures - notably peer educator groups and unions - that are able to engage fellow employees using their own languages, understandings, and group identities.

Thus, in asking whether managing HIV/AIDS in South African workplaces is just another duty the answer is that a new form of management is required in which the strengths of managerial structures and capacity is combined with the enthusiasm and peer communication strength of bottom-up initiatives. This presents enormous difficulties as South African companies take up the challenge of HIV/AIDS. It may well be tempting to drive the process 'from the top' in the belief that a strong management response will efficiently address the problem. While top-level support and resources are required, such approaches need to ensure that in wresting control of the issue they do not marginalise the responses that must be run by their own employees. Rather, ways of nurturing and supporting bottom-up responses need to be encouraged. This demands finding ways of linking top-down and bottom-up responses to HIV/AIDS that synergise the strengths of the two approaches.

This requires us all to think differently. Managers need to recognise that their employees can do things that they cannot, and employees need to understand that, in this crisis, they need management support. In South African workplaces, such an understanding - and the resulting joint effort in combating AIDS - may produce possibilities that extend beyond the immediate cause of partnership. As Putnam (1993) points out, the 'social capital' of learning to work together can be transferred by participants to different situations. South Africa badly needs new partnerships in its workplaces if it is to overcome the legacies of the past and to address the challenges of transformation and globalisation. Successfully responding to HIV/AIDS in our workplaces could well help us take steps in such a direction.

\section{ENDNOTES}

1 This paper draws on research conducted in 'Deco' during 2001 and 2002. I am grateful to Deco, especially members of the company's labour relations department, for supporting this research. Thanks to all the managers, 'aids volunteers,' trade union officials and medical personnel who gave time to complete questionnaires and give interviews. Thanks also to Karen Birdsall, Marion Stephens at the Centre for Health Policy, University of the Witwatersrand, and an anonymous referee for valuable comments. 
2 That Meeson \& van Meelis' (2000) article is also based on Eskom but entitled Not the Best Practice illustrates the problem of establishing what is best practice in the field of HIV/AIDS.

3 Readers who are not knowledgeable about HIV/AIDS are referred to Barnett \& Whiteside (2002) or Whiteside \& Sunter (2000) for information on the diseases and its likely impact in South Africa.

4 The Nedlac Code uses the term sexually transmitted diseases (STDs) - for consistency the term STI is used in this article.

5 The Nedlac Code uses the term voluntary testing rather than voluntary testing and counselling (VCT). The term VCT is used in this article.

6 Since this research was conducted, there has been a major change in the number of medical aid beneficiaries as a result of the merger and standardisation of a number of company schemes. The estimated take up of managed treatment by HIV+ members, within this larger group, is five percent (i.e. half that indicated in the table).

7 This HIV/AIDS management programme gave employees, with the company's medical aid scheme, access to antiretroviral drug treatment.

8 From the actuarial risk analysis conducted for the company in early 2002.

9 CD4 tests measure the strength of the immune system; the viral load indicates the amount of the virus in the body.

10 Some individuals would be included in the 540 but not registered on the programme because they had left the company (including cases of death) and therefore the medical aid scheme. The number of such cases was not known due to confidentiality procedures. While this group would reduce the disparity between the 540 who had accessed their HIV+ status and the 200 that were registered on the scheme, it was accepted that they were unlikely to constitute a major part of this number. Potentially increasing the disparity between the estimated number of HIV+ employees and those who had accessed their status is that some individuals may have accessed CD4 and viral load tests without a HIV+ test result (for example to reduce the 'window' period when seeking to establish their HIV status) and the possibility of fraudulent claims for CD4 and viral load counts.

11 I.e. are HIV+ and are being regularly monitored to determine the progression of the diseases and, if appropriate, are taking antiretroviral drugs.

12 See Sections 6.4 and 7 for a discussion of disclosure in the company.

13 The Nedlac Code of Good Practice recommends that companies 'endeavour to establish a wellness programme for employees affected by HIV/AIDS (13).' The exact meaning of this is open to interpretation. All that can be said from the data collected is that a majority of workplace responses reported no wellness programme in place and that the understanding of 'wellness programmes' differed. 
14 The AIDS Law Clinic, University of the Witwatersrand announced that it intended to approach the Labour Court for clarification on this issue in an attempt to remove legal uncertainty over the provision of VCT (Business Day, $4^{\text {th }}$ November 2002).

15 It is important to note that while the highly stigmatised nature of AIDS means that people are unwilling to discuss the disease openly, this does not mean that people do not know - or think they know - who has AIDS. This information is discussed or alluded during gossip or other 'closed' forms of communication. Numerous euphemisms for HIV/AIDS exist, testifying to the process by which information is transferred without open acknowledgement. A person's status can be suggested by holding up a hand with thumb and index finger crossed to silently spell out 'HIV.'

16 A third channel of communication - in addition to Peer Educators and the channel of line management - is the unions. Unions provide much of the workforce with sources of leadership that have more credibility - in HIV/AIDS, as well as other issues - than management.

\section{REFERENCES}

1 ACTUARIAL SOCIETY OF SOUTH AFRICA (2000) Actuarial Projection of the Epidemic: Summary Statistics, www.assa.org.za/ committees/aids/summarystats.htm.

2 ANGLO GOLD (2002) Anglo Gold: Facing the Challenge of HIV/AIDS.

3 ANGLO PLATINUM (2002) Annual Report 2001.

4 BARNETT, T. \& WHITESIDE, A. (2002) AIDS in the Twenty-first Century: Disease and Globalization, Palgrave Macmillan: Basingstoke.

5 BOOYSEN, F. \& MOLELEKOA, J. (2002) "The Benefits of HIV/AIDS intervention in the workplace: A case study" South African Journal of Economic and Management Sciences, 5(1): 180-202.

6 CAMPBELL, C. \& WILLIAMS, B. (2001) "Riding the tiger: Contextualising HIV prevention in South Africa" African Affairs 100: $135-40$.

7 DECO (2000) HIV/AIDS Deco Cares.

8 DEPARTMENT OF HEALTH (1999) The Electricity Supply Commission of South Africa (Eskom). HIV/AIDS and STD Directorate, HIV/AIDS Best Practice Series.

9 DEPARTMENT OF HEALTH (2002) National HIV and Syphilis Seroprevalence Survey in South Africa 2001: Summary Report

10 GOVERNMENT OF SOUTH AFRICA (1998) Employment Equity Act (Act No. 55 of 1998).

11 JOHNSON, L. \& BUDLENDER, D. (2002) HIV Risk Factors: A Review of the Demographic, Socio-economic, Biomedical and Behavioural 
Determinants of HIV Prevalence in South Africa, Centre for Actuarial Research, University of Cape Town.

12 KING COMMITTEE ON CORPORATE GOVERNANCE (2002) King Report on Corporate Governance for South Africa, Institute of Directors: Johannesburg.

13 MARAIS, H. (2000) To the Edge: AIDS Review 2000, Centre for the Study of AIDS: University of Pretoria.

14 MEDICAL RESEARCH COUNCIL (2001) The Impact of HIV/AIDS on Adult Mortality in South Africa, Burden of Disease Research Unit, MRC.

15 MEESON, A (2000) "Not so sweet: HIV/AIDS and South Africa's canefields," South African Labour Bulletin, 24(5): 43-9.

16 MEESON, A. \& VAN MEELIS. T. (2000) "Practising in parallel: Not the best practice" [Eskom], South African Labour Bulletin 24(2): 44-9.

17 NEDLAC/DEPARTMENT OF LABOUR (2000) Employment Equity Act: Code of Good Practice on Key Aspects of HIV/AIDS and Employment.

18 PUTNAM, R. (1993) Making Democracy Work: Civic Traditions in Modern Italy. Princeton, NJ: Princeton University Press.

19 ROSEN, S.; SIMON, J.; THEAR, D. \& VINCENT, J. (2000) "Care and treatment to extend the working lives of HIV-positive employees: Calculating the benefits to business," South African Journal of Science 96(6): 300-4.

20 SOUTH AFRICAN BUSINESS COALITION ON HIV/AIDS (2002) Evaluation of Workplace Responses to HIV/AIDS in South Africa: A Rapid Situation Analysis. Sabcoha, DFID and Deloitte \& Touch Human Capital Corporation.

21 SCHNEIDER, H. \& STEIN, J. (2001) "Implementing AIDS policy in post-apartheid South Africa," Social Science and Medicine, 52:723-31.

22 UNAIDS (1999) Sexual behavioural change for HIV: Where have theories taken us?

23 UNAIDS (2000) The Business Response to HIV/AIDS: Impact and Lessons Learned. UNAIDS, The Global Business Council on HIV/AIDS and The Prince of Wales Business Leaders Forum.

24 UNAIDS (2002a) Report on the Global HIV/AIDS Epidemic 2002.

25 UNAIDS (2002b) The Private Sector Response to the Epidemic: Debswana - a Global Benchmark, UNAIDS Best Practice Collection.

26 WARD, D. (1999) The AmFAR AIDS Handbook, New York: W.W. Norton \& Company.

27 WILLIAMS, B.; GILGEN, D.; CAMPBELL, C.; TALJAARD, D. \& MACPHAIL, C. (2000) The Natural History of HIV/AIDS in South Africa: A Biomedical and Social Survey, Johannesburg: CSIR.

28 WHITESIDE, A. \& SUNTER, C. (2000) AIDS: The Challenge for South Africa, Human \& Rousseau Tafelberg: Cape Town. 